\title{
Pengaruh Jenis dan Konsentrasi Aditif Terhadap Karakteristik Faktis Coklat dari Minyak Jarak Pagar
}

\author{
Santi Puspitasari*, Hani Handayani, dan Yoharmus Syamsu \\ Pusat Penelitian Karet \\ Jalan Salak no.1 Bogor 16151, Telp (0251) 8319817, Fax (0251) 8324047 \\ Email : shanty_bptkbgr@yahoo.co.id
}

\begin{abstract}
Processing aid is an important chemical which is added to the rubber compound preparation. This ingredient will facilitate rubber mixing with other rubber chemicals. Brown factice is a processing aid used in the rubber article industries, especially in the rubber hose manufacture. This material is synthesized by polymerization of vegetable oil with sulfur at certain temperature. This reaction produces a crosslinking of the triglyseride molecules connected by sulfur. The crosslink causes the brown factice texture become elastic or rubberlike. The condition of the polymerization reaction and the compotition of reactant affect the brownfactice quality. The classification of brown factice is based on its visual and chemical properties. The aim of the research was to study brown factice formulation which produce the optimum polymerization condition and the best quality of brown factice. In this experiment the brown factice was synthesized from Jatropha curcas oil at the laboratory scale using TMTD and ZDEC accelerators, by 1.0 pho dosage. The polymerization was conducted at $140^{\circ} \mathrm{C}$ on 30.0 pho of sulphur, while the $\mathrm{ZnO}$ and $\mathrm{Na}_{2} \mathrm{CO}_{3}$ dosage was varied at 0.25 and 0.50 pho. The reaction time, temperature, and exothermic step were observed conscientiously during the reaction. The brown factice rendemen was calculated and its quality was characterized. The result showed that the condition of the polymerization reaction using ZDEC and TMTD as accelerator was not significantly different, but the quality of brown factice using ZDEC was better than TMTD (brighter color, lower free sulphur content, and acetone extract content). The best quality of brown factice was obtained from the formulation of ZDEC as accelerator, 0.5 pho of $\mathrm{ZnO}$ and 0.5 pho of $\mathrm{Na}_{2} \mathrm{CO}_{3}$.
\end{abstract}

Keywords: Brown factice, Jatropha curcas oil

Bahan bantu olah merupakan salah satu bahan kimia karet yang ditambahkan dalam pembuatan kompon. Bahan bantu olah mampu mempermudah pencampuran karet dengan bahan kimianya. Faktis coklat termasuk dalam golongan bahan bantu olah yang digunakan dalam industri barang jadi karet, teruma industri selang karet. Faktis coklat dibuat melalui polimerisasi minyak nabati dengan sulfur pada suhu tertentu. Reaksi tersebut akan menghasilkan ikatan silang antara trigliserida yang dijembatani oleh sulfur. Ikatan silang mengakibatkan faktis coklat bertekstur kenyal seperti karet. Kondisi reaksi polimerisasi dan komposisi reaktan sangat menentukan mutu faktis coklat dengan spesifikasi mutu terbaik. Pada percobaan ini, faktis coklat disintesis dari minyak jarak pagar pada skala laboratorium menggunakan bahan pencepat jenis TMTD dan ZDEC pada dosis 1 bsm. Polimerisasi dijalankan pada suhu $140^{\circ} \mathrm{C}$ dengan penambahan 30 bsm sulfur, dosis $\mathrm{ZnO}$ dan $\mathrm{Na}_{2} \mathrm{CO}_{3}$ divariasikan pada $0,25-0,5 \mathrm{bsm}$. Waktu reaksi dan kondisi polimerisasi diamati selama reaksi berlangsung. Rendemen faktis dihitung kemudian dikarakterisasi mutunya. Hasil penelitian menunjukkan bahwa kondisi reaksi polimerisasi dengan TMTD maupun ZDEC tidak berbeda nyata tetapi mutu faktis coklat yang disintesis dengan ZDEC lebih baik dibandingkan dengan TMTD (warna lebih cerah, kadar sulfur bebas dan kadar ekstrak aseton lebih rendah). Faktis coklat dengan mutu terbaik diperoleh dari formulasi ZDEC sebagai bahan pencepat, $0,5 \mathrm{bsm} \mathrm{ZnO}$ dan $0,5 \mathrm{bsm} \mathrm{Na}_{2} \mathrm{CO}_{3}$.

Kata kunci : Faktis coklat, minyak jarak pagar

\section{Pendahuluan}

Bahan bantu olah merupakan salah satu bahan kimia karet yang ditambahkan dalam pembuatan kompon karet. Fungsi utama bahan bantu olah adalah mempermudah pencampuran karet dengan bahan kimianya sehingga cepat membentuk campuran kompon karet yang homogen. Bahan bantu olah ditambahkan dalam kompon karet pada dosis yang relatif kecil tanpa mempengaruhi sifat fisika barang jadi karet (Johnson, 2001). Bahan bantu olah terdiri atas homogenizing agent, peptizer, tackifiers, platicizer, dan dispersing agent (Nagdi, 1993). Salah satu contoh bahan bantu olah yang banyak digunakan di industri manufaktur barang jadi karet terutama industri selang karet adalah faktis coklat.

Faktis coklat disintesis melalui reaksi polimerisasi antara minyak nabati dengan sulfur atau sulfur monoklorida pada suhu tertentu (Whelan, 1994). Reaksi minyak nabati dengan sulfur pada suhu tinggi akan membentuk faktis coklat sedangkan dengan sulfur monoklorida pada suhu rendah akan diperoleh faktis 
putih. Konsentrasi sulfur yang ditambahkan tergantu pada tingkat ketidak-jenuhan minyak nabati (Methven, 1991). Umumnya sulfur ditambahkan pada konsentrasi 10-30\% (Whelan, 1994). Reaksi polimerisasi tersebut disebut juga dengan istilah reaksi vulkanisasi. Melalui reaksi vulkanisasi akan terjalin ikatan silang antara trigliserida yang dijembatani oleh sulfur. Ikatan silang menyebabkan faktis coklat bertektur kenyal seperti karet. Bahan kimia tambahan (aditif) dalam sintesis faktis coklat turut mempengaruhi mekanisme reaksi dan mutu faktis coklat yang dihasilkan.

Bahan kimia yang ditambahkan dalam reaksi polimerisasi pembentukan faktis coklat antara lain $\mathrm{Na}_{2} \mathrm{CO}_{3}, \mathrm{ZnO}$, dan bahan pencepat. $\mathrm{Na}_{2} \mathrm{CO}_{3}$ berfungsi sebagai bahan penetral asam lemak bebas dalam minyak nabati dan pembentuk tekstur berpori pada faktis coklat. Reaksi penetralan asam lemak bebas dengan $\mathrm{Na}_{2} \mathrm{CO}_{3}$ mengikuti persamaan reaksi kimia sebagai berikut :

$$
\mathrm{RCOOH}+\mathrm{Na}_{2} \mathrm{CO}_{3} \rightarrow \mathrm{RCOONa}+\mathrm{H}_{2} \mathrm{CO}_{3}
$$

Asam karbonat selanjutnya akan terurai menjadi $\mathrm{CO}_{2}$. Senyawa $\mathrm{CO}_{2}$ turut berperan dalam pembentukan spon dalam tekstur berpori faktis coklat. Peranan $\mathrm{ZnO}$ dalam reaksi pembentukan faktis coklat sebagai bahan pengaktif reaksi vulkanisasi. Bahan pengaktif dan bahan pencepat akan bekerja sama mempercepat laju reaksi vulkanisasi. Fungsi $\mathrm{ZnO}$ akan semakin optimal jika dikombinasikan dengan asam stearat. Pada reaksi vulkanisasi faktis coklat, penambahaan asam stearat berasal dari kandungan asam lemak dalam minyak nabati. $\mathrm{Na}_{2} \mathrm{CO}_{3}$ dan $\mathrm{ZnO}$ merupakan senyawa penghasil abu karena mengandung persenyawaan karbonat dan oksida. Sehingga konsentrasi kedua bahan tersebut akan sangat berpengaruh terhadap kadar abu faktis coklat. Kadar abu yang diizinkan dalam faktis coklat komersial sebesar $1,5 \pm 0,5 \%$.

Stem (1967) dalam Erhan \& Kleiman (1990) menyatakan bahwa bahan pencepat dapat meningkatkan laju kombinasi sulfur dengan cara memecah bentuk stabil dari sulfur menjadi sulfida dan polisulfida kemudian melepaskan sulfur bebas yang aktif. Bahan pencepat turut meningkatkan effisiensi dan pemanfaatan sulfur sebagai bahan pembentuk ikatan silang dan menghasilkan struktur jaringan yang lebih sederhana (Erhan \& Kleiman, 1990). Jenis bahan pencepat yang ditambahkan dalam formulasi faktis coklat identik dengan bahan pencepat untuk reaksi vulkanisasi polimer karet. Bahan pencepat seringkali ditambahkan ke dalam pembuatan kompon karet untuk meningkatkan laju sehingga mempersingkat waktu reaksi vulkanisasi molekul karet. Secara umum bahan pencepat kompon karet dibedakan menjadi bahan pencepat primer dan sekunder/ultra. Kelompok bahan pencepat primer diwakili oleh guanidine dan aldehydeamine. Bahan pencepat ultra misalnya benzothiazole, thiuram disulfide, dan garam dari asam-asam thio (thiourea) (Chandrasekaran, 2010). Rasio antara bahan pencepat dengan sulfur sebagai bahan pembentuk ikatan silang sangat berpengaruh terhadap sistem vulkanisasi dan derajat ikatan silang yang terbentuk dalam molekul- molekul polimer. Setiap jenis bahan pencepat juga memiliki mekanisme reaksi vulkanisasi yang spesifik.

TMTD (Tetramethyl thiuram disulfide) merupakan jenis bahan pencepat ultra dari golongan thiuram. TMTD disintesis melalui reaksi oksidasi garam dari dimethyldithiocarbamic acid. Dalam reaksi vulkanisasi karet, TMTD dapat digunakan tanpa penambahan sulfur karena TMTD dapat berfungsi sebagai donor sulfur (White \& De, 2001). Dekomposisi termal TMTD akan menghasilkan TMTU, $\mathrm{CS}_{2}$, dan sulfur bebas yang aktif (Willoughby, 1999). ZDEC (Zinc diethyl dithiocarbamat) juga termasuk bahan pencepat ultra dari kelas dithiocarbamate. ZDEC umumnya digunakan untuk lateks. Dekomposisi termal ZDEC tidak membentuk sulfur bebas aktif. Berdasarkan pada hasil reaksi dekomposisi termal kedua bahan pencepat tersebut, maka penambahannya dalam sintesis faktis coklat akan berpengaruh terhadap mutu faktis coklat terutama kadar sulfur bebasnya.

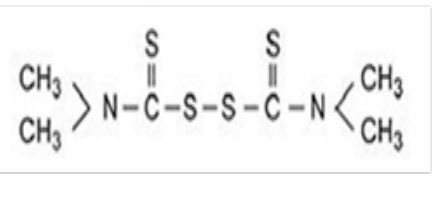

TMTD

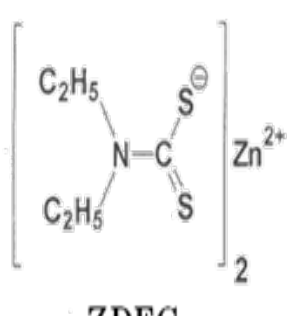

ZDEC
Gambar 1. Struktur molekul TMTD dan ZDEC

Sifat kimia faktis coklat menjadi faktor penentu dalam pengkategorian mutu faktis coklat komersial selain dinilai berdasarkan visualisasinya. Faktis coklat komersial dikatakan bermutu tinggi jika memiliki warna coklat yang tidak terlalu gelap, bertekstur kenyal namun tidak lengket. Ditinjau dari sifat kimianya, kadar ekstrak aseton $>35 \%$, kadar sulfur bebas maksimal sebesar 1,5\%. Kadar abu diizinkan dalam faktis coklat komersial sebesar $1,5 \pm 0,5 \%$ dan $\mathrm{pH}=7$ (netral). Umumnya faktis coklat ini dihasilkan dari reaksi yang berjalan cepat (waktu reaksi relatif singkat) dan dapat memberikan kenaikan suhu eksotermis yang tinggi.

Pada penelitian ini akan dipelajari pengaruh dosis $\mathrm{ZnO}$ dan $\mathrm{Na}_{2} \mathrm{CO}_{3}(0,25-0,50 \mathrm{bsm})$ serta pemilihan jenis bahan pencepat (TMTD dan ZDEC) dalam formulasi reaktan pembuatan faktis coklat dari minyak jarak pagar pada skala laboratorium terhadap kondisi reaksi serta mutu visual dan kimiawi faktis coklat.

\section{Metodologi.}

Penelitian telah dilakasanakan di Unit Laboratorium Penelitian Pusat Penelitian Karet selama 4 bulan terhitung sejak bulan April hingga Juli 2010. Bahan utama yang digunakan terdiri atas minyak jarak pagar yang diperoleh dari Pabrik Gula PT. Jatitujuh Cirebon Jawa Barat. Bahan pendukung meliputi sulfur, $\mathrm{ZnO}, \mathrm{Na}_{2} \mathrm{CO}_{3}$, TMTD dan ZDEC pada spesifikasi teknis diperoleh dari CV Indrasari Bogor. Reaktor polimerisasi faktis coklat pada skala laboratorium berbentuk silinder glass berkapasitas dua 


\begin{tabular}{ccccc}
\hline \multicolumn{3}{c}{ Dosis, bsm } & t reaksi, \\
\cline { 1 - 3 } $\begin{array}{c}\mathrm{Na}_{2} \mathrm{C} \\
\mathrm{O}_{3}\end{array}$ & $\mathrm{ZnO}$ & $\begin{array}{c}\text { Rendemen } \\
\%\end{array}$ & $\begin{array}{c}\text { T eksoterm } \\
{ }^{\circ} \mathrm{C}\end{array}$ \\
\cline { 2 - 2 } 0,25 & 0,25 & 30 & 82 & 186 \\
& 0,50 & 60 & 89 & 182 \\
0,50 & 0,25 & 35 & 92 & 192 \\
& 0,50 & 29 & 93 & 164 \\
0,25 & 0,25 & 53 & 95 & 185 \\
& 0,50 & 51 & 98 & 185 \\
0,50 & 0,25 & 60 & 95 & 170 \\
\hline
\end{tabular}

liter dilengakapi dengan pengaduk mekanis dan penangas minyak.

Perlakukan percobaan adalah sebagai berikut : 100 gram minyak jarak pagar dituangkan ke dalam reaktor berpengaduk. Minyak jarak pagar ditambah dengan $\mathrm{Na}_{2} \mathrm{CO}_{3}$ kemudian dipanaskan dari suhu ruang hingga mencapai suhu reaksi pada $140^{\circ} \mathrm{C}$. 3 menit setelah tercapai suhu reaksi, ke dalam minyak jarak pagar yang telah dinetralkam dengan $\mathrm{Na}_{2} \mathrm{CO}_{3}$ secara berturut-turut ditambah dengan $\mathrm{ZnO}$, bahan pencepat TMTD atau ZDEC, dan sulfur. Konsentrasi $\mathrm{Na}_{2} \mathrm{CO}_{3}$ dan $\mathrm{ZnO}$ divariasikan sebanyak 0,25 dan 0,5 bsm. Sedangkan bahan pencepat ditambahkan pada dosis 1 bsm dan 30 bsm untuk sulfur. Pengadukan terus dijalankan hingga akhir reaksi, tetapi pemanasan dihentikan sesaat setelah melewati titik eksotermis tertinggi. Kondisi reaksi dan perubahan fasa serta warna yang terjadi diamati selama reaksi berlangsung. Pada akhir reaksi faktis coklat yang terbentuk berupa pasta yang akan memadat setelah didinginkan pada suhu ruang. Padatan faktis coklat digerus menjadi serbuk selanjutnya dihitung rendemen, dikarakterisasi visualisasi serta sifat kimianya. Karakteristik visual meliputi warna dan tektur. Untuk karakteristik sifat kimia mencangkup kadar ekstrak aseton, kadar sulfur bebas, kadar abu, dan pH. Penentapan kondisi optimal polimerisasi faktis coklat ditentukan berdasarkan kualitas faktis coklat terbaik. Kualitas faktis coklat sangat dipengaruhi oleh formulasi reaktan dalam pembentukan faktis coklat.

\section{Hasil dan Pembahasan.}

\subsection{Kondisi Reaksi Polimerisasi Pembentukan Faktis Coklat}

Kondisi reaksi yang diamati selama pembentukan faktis coklat mencangkup waktu reaksi, suhu eksotermis tertinggi dan rendemen yang diperoleh. Waktu reaksi diperhitungkan mulai penambahan bahan kimia faktis hingga akhir reaksi dimana faktis coklat telah berubah menjadi pasta berwarna coklat dan suhu reaksi kembali ke titik awal setelah melewati suhu eksotermis tertinggi. Perhitungan rendemen faktis coklat mengikuti rumus (2) sebagai berikut :

Rendemen $=\frac{\text { berat faktis coklat }}{\text { total berat reaktan }} \times 100 \%$
Ringkasan hasil pengamatan reaksi vulkanisasi pembentukan faktis coklat ditunjukkan pada Tabel 1 .

Tabel 1. Kondisi sinthesis faktis coklat

$\mathrm{ZnO}$ dan bahan pencepat berperan penting dalam menentukan waktu reaksi faktis coklat. Kombinasi $\mathrm{ZnO}$, bahan pencepat, dan sulfur dapat mempersingkat waktu reaksi. Dari Tabel 1 diketahui bahwa bahan pencepat ZDEC (30-60 menit) menghasilkan waktu reaksi lebih singkat daripada reaksi menggunakan TMTD (40-60 menit). Rata-rata suhu eksotermis tertinggi antara kedua kondisi reaksi tidak berbeda nyata yaitu berada pada kisaran $180^{\circ} \mathrm{C}$. Kondisi eksotermis terjadi karena adanya pelepasan energi dari atom sulfur untuk bereaksi dengan atom karbon pada trigliserida yang memiliki ikatan rangkap.

Rendemen faktis coklat yang diperoleh untuk reaksi mengunakan ZDEC rata-rata sebesar $89 \%$ dan $96 \%$ untuk reaksi dengan TMTD. Rendemen yang tinggi berkaitan dengan kesempurnaan reaksi.

\subsection{Visualisasi Fisik Faktis Coklat.}

Visualisasi fisik faktis coklat dinilai berdasarkan warna dan tekstur faktis coklat. Warna faktis coklat komersial antara lain putih, kuning, dan coklat. Sedangkan tekstur faktis diketahui mulai bertektur kenyal hingga keras. Hasil penilaian visualisasi fisik faktis coklat ditunjukkan pada Tabel 2 sebagai berikut.

Tabel 2. Visualisasi fisik faktis coklat.

\begin{tabular}{cccc}
\hline \multicolumn{2}{c}{ Dosis, bsm } & \multicolumn{2}{c}{ Visualisasi Faktis } \\
\hline $\mathrm{Na}_{2} \mathrm{CO}_{3}$ & $\mathrm{ZnO}$ & Warna & Tekstur \\
\hline \multirow{4}{*}{0,25} & 0,25 & Bahan & Cencepat ZDEC \\
& 0,50 & Coklat gelap & Kenyal \\
0,50 & 0,25 & Coklat gelap & Kenyal \\
& 0,50 & Coklat gelap & Kenyal \\
& Bahan Pencepat TMTD & \\
0,25 & 0,25 & Coklat & Kenyal \\
& 0,50 & Coklat gelap & Kenyal \\
0,50 & 0,25 & Coklat & Kenyal \\
& 0,50 & Coklat & Kenyal \\
\hline
\end{tabular}

Faktor penentu warna dan tekstur faktis coklat terdiri atas konsentrasi sulfur, kandungan asam lemak tak jenuh dalam minyak jarak pagar, dan suhu reaksi vulkanisasi. Dalam penelitian ketiga faktor ditetapkan konstan sehingga menghasilkan faktis coklat yang memiliki kemiripan visualisasi fisik. Warna faktis coklat yang disintesis dengan penambahan $0,25 \mathrm{bsm} \mathrm{Na}_{2} \mathrm{CO}_{3}$ dan 0,50 bsm $\mathrm{ZnO}$ memiliki warna yang lebih gelap dibanding faktis coklat lainnya. Hal ini disebabkan karena kosentrasi $\mathrm{ZnO}$ yang tinggi meningkatkan effisiensi reaksi vulkanisasi. Semakin optimal berjalannya reaksi maka terbentuknya ikatan silang semakin banyak sehingga warna faktis coklat semakin coklat tetapi tidak sampai menghitam. Faktis coklat yang terbentuk bersifat kenyal 
namun tidak lengket sehingga dapat dihancurkan menjadi serbuk.

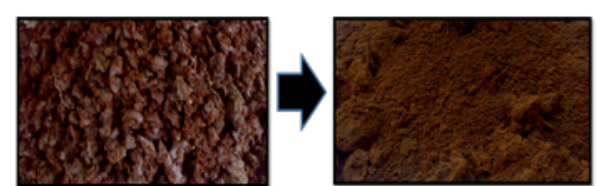

Gambar 2. Faktis coklat sebelum dan setelah penggerusan

\subsection{Sifat Kimia Faktis Coklat}

Sifat kimia faktis coklat merupakan salah satu acuan dalam penggolongan mutu. Menurut Loganathan (1998), parameter dalam analisis sifat kimia faktis coklat meliputi kadar ekstrak aseton, kadar sulfur bebas, kadar abu, dan pH. Kadar ekstrak aseton menjadi acuan utama dalam penggolongan mutu faktis coklat. Hasil analisis sifat kimia faktis coklat disajikan pada Tabel 3.

Tabel 3. Sifat kimia faktis coklat.

\begin{tabular}{|c|c|c|c|c|c|}
\hline \multicolumn{2}{|c|}{ Dosis, bsm } & \multirow{2}{*}{$\begin{array}{c}\text { Kadar } \\
\text { ekstrak } \\
\text { aseton, } \\
\%\end{array}$} & \multirow{2}{*}{$\begin{array}{c}\text { Kadar } \\
\text { sulfur } \\
\text { bebas, } \\
\%\end{array}$} & \multirow{2}{*}{$\begin{array}{c}\text { Kadar } \\
\text { abu, } \\
\%\end{array}$} & \multirow{2}{*}{$\mathrm{pH}$} \\
\hline $\begin{array}{c}\mathrm{Na}_{2} \mathrm{C} \\
\mathrm{O}_{3} \\
\end{array}$ & $\mathrm{ZnO}$ & & & & \\
\hline \multicolumn{6}{|c|}{ Bahan Pencepat ZDEC } \\
\hline \multirow{2}{*}{0,25} & 0,25 & 29,93 & 3,08 & 1,92 & 8,73 \\
\hline & 0,50 & 30,23 & 3,13 & 1,24 & 8,70 \\
\hline \multirow{2}{*}{0,50} & 0,25 & 27,99 & 2,80 & 1,61 & 9,40 \\
\hline & 0,50 & 27,41 & 2,56 & 1,56 & 8,01 \\
\hline \multicolumn{6}{|c|}{ Bahan Pencepat TMTD } \\
\hline \multirow{2}{*}{0,25} & 0,25 & 44,64 & 4,62 & 0,46 & 6,88 \\
\hline & 0,50 & 33,92 & 3,53 & 0,63 & 6,76 \\
\hline \multirow{2}{*}{0,50} & 0,25 & 32,59 & 5,24 & 0,63 & 8,04 \\
\hline & 0,50 & 30,68 & 4,37 & 0,92 & 6,84 \\
\hline
\end{tabular}

Kadar ekstrak aseton menunjukkan jumlah minyak yang tidak tersabunkan, sisa sulfur yang tidak bereaksi, dan bagian gliserida tersulfurisasi yang terekstrak dari dalam faktis coklat (Erhan \& Kleiman, 1990). Secara umum kadar ekstrak aseton faktis coklat yang disintesis menggunakan bahan pencepat ZDEC (27-30\%) lebih rendah dibandingkan pada reaksi dengan TMTD (3044\%). Kadar ekstrak aseton faktis coklat memenuhi syarat faktis coklat komersial grade II karena berada pada kisaran 20-35\% (Erhan \& Kleiman, 1990). Hal serupa ditunjukkan kadar sulfur bebas, faktis coklat dengan ZDEC (2,5-3,1\%) memiliki kadar abu lebih rendah dari TMTD (3,5-5,2\%). Perbedaan dari kedua nilai disebabkan karena perbedaan dalam kadar total sulfur . Kadar total sulfur bebas diperoleh dari hasil penjumlahan sulfur berikatan, sisa sulfur tidak bereaksi dengan sulfur bebas akibat dekomposisi termal bahan pencepat. Adanya sulfur bebas akibat dekomposisi TMTD akan menambah jumlah total sufur menyebabkan kadar ekstrak aseton dan kadar sulfur bebas dalam faktis coklatyang disintesis dengan penambahan TMTD cenderung tinggi.

Kadar sulfur bebas yang tinggi dalam faktis coklat tidak diharapkan karena akan memberikan dampak negatif saat faktis coklat ditambahkan ke dalam pembuatan kompon karet. Sulfur bebas dapat menyebakan terjadinya overcuring (Erhan \& Kleiman, 1990) dan sulfur blooming di permukaan barang jadi karet. Overcuring harus dihindari karena dapat menurunkan sifat fisik barang jadi karet terutama barang jadi karet yang tidak tahan terhadap proses oksidasi pada suhu tinggi.

Kadar abu dan $\mathrm{pH}$ faktis coklat sangat bergantung pada konsentrasi penambahan $\mathrm{ZnO}$ dan $\mathrm{Na}_{2} \mathrm{CO}_{3}$. Konsentrasi sebesar 0,25 bsm memberikan kadar abu relatif lebih rendah dibandingkan $0,5 \mathrm{bsm}$. Seluruh formulasi reaktan dalam pembentukan faktis coklat menghasilkan kadar abu (0,46-1,92\%) yang memenuhi persyaratan faktis coklat komersial. Dari hasil pengukuran pH dapat diketahui bahwa faktis coklat yang disintesis pada 0,25 dan 0,5 bsm $\mathrm{Na}_{2} \mathrm{CO}_{3}$ bahan pencepat jenis ZDEC cenderung bersifat basa $(\mathrm{pH}=8,0-9,4)$ sedangkan $\mathrm{pH}$ faktis coklat dengan TMTD mendekati netral $(\mathrm{pH}=$ $6,7-8,0)$.

\section{Kesimpulan.}

Formulasi reaktan dalam sintesis faktis coklat dari minyak jarak pagar pada skala laboratorium yang menghasilkan faktis coklat dengan mutu terbaik diperoleh dari formulasi dengan penambahan ZDEC sebagai bahan pencepat, 0,5 bsm $\mathrm{ZnO}$ dan 0,5 bsm $\mathrm{Na}_{2} \mathrm{CO}_{3}$. Faktis coklat tersebut disintesis selama 29 menit dengan suhu eksotermis tertinggi mencapai $164^{\circ} \mathrm{C}$, dan diperoleh rendemen sebesar $93 \%$. Secara visual penampakan faktis coklat berwarna coklat gelap (coklat tua) dan bertekstur kenyal. Kadar ekstrak aseton, kadar sulfur bebas, kadar abu secara berturut-turut sebesar $27,41 \% ; 2,56 \%$; dan $1,56 \%$. Sedangkan $\mathrm{pH}$ terukur bersifat basa $(\mathrm{pH}=8,01)$.

\section{Ucapan Terimakasih}

Ucapan terimakasih disampaikan kepada Direksi beserta seluruh staf Pabrik Gula Jati Tujuh, PT. Rajawali II Cirebon, Jawa Barat, atas izinnya untuk memperoleh minyak jarak pagar sebagai bahan baku utama dalam penelitian ini. Penghargaan tinggi turut disampaikan pada Kementrian Riset dan Teknologi atas Program Insentif TA 2010 dalam pendanaan riset.

\section{V.Daftar Pustaka.}

Chandrasekaran, V.C., 2010, Rubber as a Construction Material for Corrosion Protection, A Comprehensive Guide for Process Equipment Designers, Scrivener Publishing LLC, Massachusetts.

Erhan, S.M., \& Kleiman, R., 1990, Vulcanized Meadowfoam Oil, Journal of the American Oil Chemist Society Vol.67 No.10, Oktober: 670-674

Johson, P.S., 2001, Rubber Processing : an Introduction, Hanser Gadner Publication Inc, USA.

Loganathan, K.S., 1998, Rubber Engineering, Tata McGraw Hill Publishing Company Ltd, New Delhi.

Methven, J.M., 1991, Current Developments in Materials Technology and Engineering Report 43. Polymeric Materials from Renewable Resources. Vol 4 No 7 
1991, Tyretech '90 : Papers from a two-day seminar, $5^{\text {th }}-6^{\text {th }}$ November 1990

Nagdi, k., 1993, Rubber as an Engineering Material: Guideline for User, Hanser Publ, Germany.

Stem, H.J., 1967, Rubber, Natural and Synthetic, Maclaren \& Sons Ltd, London

Willoughby, B., 1999, The Rationalisation and Prediction of the Components of Rubber Fume, Conference Proceedings : Hazards in the European Rubber Industry - An Assessment of Exposure Risk, p. 41

Whelan, T., 1994, Polymer Technology Dictionary, Chapman \& Hall, London

White, J.R., \& De, S.K., 2001, Rubber Technologist's Handbook, Rapra Technology Ltd, Shorpshire 